\title{
Adult Diapause in Coleoptera
}

\author{
Ivo Hodek \\ Institute of Entomology, Biological Centre, Academy of Sciences, 37005 Ceske Budejovice, Czech Republic
}

Correspondence should be addressed to Ivo Hodek, hodek@entu.cas.cz

Received 15 September 2011; Accepted 11 October 2011

Academic Editor: Ai-Ping Liang

Copyright () 2012 Ivo Hodek. This is an open access article distributed under the Creative Commons Attribution License, which permits unrestricted use, distribution, and reproduction in any medium, provided the original work is properly cited.

Recent studies dealing with adult (reproductive) diapause in the Coleoptera are reviewed, as a kind of supplement to the classic compendia. In the first two sections, the general characteristics of adult diapause are described and principal terms explained. Original articles dealing with 19 species from nine coleopteran families (Coccinellidae, Chrysomelidae, Bruchidae, Curculionidae, Carabidae, Silphidae, Scolytidae, Scarabaeidae, and Endomychidae) are reviewed. Finally attempts are made at generalisations from the papers reviewed, and hypotheses on diapause evolution are inferred. A polyphenic character of diapause is a prominent feature in C. septempunctata and L. decemlineata, but has been found also in other Coleoptera and in insects generally and often generates voltinism heterogeneity within populations.

\section{Introduction}

Adult diapause is the most common form of diapause in Coleoptera. It occurs in about $90 \%$ of beetle species [1], belonging mostly to the families of Coccinellidae, Chrysomelidae, and Curculionidae, and partly also Carabidae (the so-called carabid "autumn breeders" diapause as larvae). Another insect order with a high incidence of species entering diapause in the adult stage, is the Heteroptera with about $70 \%$ species. The lowest incidence of adult diapause is among species in the orders Lepidoptera and Hymenoptera (about 5\% each).

\section{General Remarks on Adult/Reproductive Diapause}

To save space in discussions of individual species and avoid repetition, we describe the common characteristics here. (For more details see $[1,2]$.)

Diapause is an adaptive arrestment of development that helps synchronize active stages with suitable environmental conditions and so increase survival potential during unfavourable periods of the year. Insects that diapause as adults, the larvae and the young adults, develop when the food resources are present. For the stressful period without food (often lasting many months) adults prepare in time by accumulating reserves (lipids, glycogen, proteins) and substances needed for resistance to future hazardous changes of environmental conditions. To begin early enough before the start of the dangerous period, diapause is induced by signals heralding the arrival of the unfavourable season; usually the cue is photoperiodic. Short (decreasing) day length serves as a signal of approaching winter and induces winter diapause (hibernation). In contrast, long-day photoperiods announce summer and induce estivation/summer diapause. Temperature and other environmental conditions act during the sensitive stage in concert with photoperiod in diapause induction or aversion (= prevention).

Such regulation is typical for facultative diapause that can, but need not, be entered in each generation. Quite often, however, the genetically fixed propensity is so strong that diapause, may be obligatory, is entered under any environmental conditions. Usually a population is not genetically homogeneous: both tendencies may be mixed, as we will see below, for example, in Coccinella septempunctata or Leptinotarsa decemlineata.

To terminate diapause, the insect has to go through diapause development, that is, horotelic processes of physiogenesis that often proceed best at temperatures in the range of $5-10^{\circ} \mathrm{C}$, but cold is not always a prerequisite for the resumption of development [3]. In many cases, diapause may be terminated by tachytelic processes of termination that is 
due to some environmental stimuli, such as a temperature increase or rainfall in case of summer diapause.

For quite a long period diapause research was focused only on hibernation/winter diapause, as the traditional view equated diapause with resistance to freezing. Estivation/ summer diapause was long neglected, although it is rather common [4]. Quite often the terms hibernation versus estivation do not respond well to timing of seasons in the field: winter diapause may begin as early as in midsummer, as we will see below in several ladybird species.

Also, while hibernation lasts until spring, its diapause phase in temperate insect populations dwindles into postdiapause quiescence around the winter solstice. In this phase the morphological development of insects is arrested only directly by low temperature (or absence of food), and in spring (or by transfer to suitable laboratory conditions) morphological development is resumed.

The most conspicuous feature of adult diapause (often termed reproductive diapause) is the suppression of reproductive functions: maturing of ovaries and male accessory glands, and mostly also mating activity. Endocrinological regulatory pathways in adult diapause begin in the neurosecretory cells of brain whose axons terminate in corpora cardiaca. The pathway continues in another endocrinological organ, the corpora allata, where juvenile hormone is produced that regulates the activity of reproductive organs. In adults destined for diapause, food consumed is not used for maturation of gonads but for accumulating reserves. Thus the ovaries consist of threadlike ovarioles, so hidden in the much-enlarged fat body that they are sometimes difficult to find in dissection.

The above general traits were revealed in several coleopteran species that were studied in detail for many decades and published in series of papers, such as the studies on Leptinotarsa decemlineata and Coccinella septempunctata. The classic papers are not reviewed here as they are reviewed in the above-mentioned compendia $[1,2]$. Here we focus on more recent findings, mostly those published in the last two decades. It may be warned that the basic paradigm of diapause, built in the previous century, had not yet been broken.

\section{Coccinellidae}

3.1. Coccinella septempunctata $L$. Among ladybirds, adult diapause has evidently been most studied in the originally Palaearctic species Coccinella septempunctata, the seven spot, that has in two recent decades invaded the Nearctic region and attracted attention of researchers there (e.g., [5]). Both in Europe and USA C. septempunctata has been found heterogeneous as to the induction of diapause (see Section 1).

In Bohemia $\left(50^{\circ} \mathrm{N}\right.$, Western Czech Republic), the population in the autumn consists of two fractions. Although in some years aggregations of both sexes of dormant $C$. septempunctata may be found in their hibernation quarters in grass tussocks from early August onwards, one can also find actively feeding coccinellids on vegetation with aphids (often on different weeds, such as Carduus spp. and Daucaceae) for the whole of September and into early October [6]. The physiological condition of these two fractions was determined by dissection immediately after sampling and after rearing. Whereas the alimentary canal in the dormant beetles was empty of food and there were no traces of vitellinization in the ovaries, the digestive tract was full of food in more than half of the active adults sampled and $13-20 \%$ of females possessed vitellinized oocytes or even eggs. The difference between the dormant and active beetles became striking when they were reared for three weeks under long days, at $19-22.5^{\circ} \mathrm{C}$ with plentiful aphid food; the ovarioles of about $85-90 \%$ of dormant females remained without any vitellinization, while about $90 \%$ of the females collected on plants possessed vitellinized oocytes after rearing [6].

Dissections in mid-July of females collected outdoors a fortnight after adult emergence indicated a strong tendency to univoltinism: $84-93 \%$ of the females, entered diapause. The offspring of overwintered adults (F 1) also displayed a high incidence of diapause despite rearing under longday conditions of $16 \mathrm{~L}: 8 \mathrm{D}$ or $18 \mathrm{~L}: 6 \mathrm{D}$ with a surplus of suitable prey. When such experiments were repeated in five years the incidence of diapause in $\mathrm{F} 1$ fluctuated between 60 and 90\%. A gradual decrease in diapause incidence across generations suggests selection against a propensity for obligatory diapause under long days [6].

A dominant effect of photoperiod and its modification by temperature was documented in samples from the selected lines. Under long days diapause was prevented in most females and $87-96 \%$ females reproduced in spite of low temperatures $\left(18\right.$ or $18.5^{\circ} \mathrm{C}$, resp.). Under short days of $12 \mathrm{~L}: 12 \mathrm{D}$ or $8 \mathrm{~L}: 16 \mathrm{D}$, diapause incidence was high (85$94 \%$ ) at low temperature (about $18^{\circ} \mathrm{C}$ ), but low at high temperature: at temperatures alternating between $24-25^{\circ} \mathrm{C}$ (night) and $27-28^{\circ} \mathrm{C}$ (day) only $10 \%$ entered diapause.

In central Europe and the Paris region (France), the progress of diapause development in C. septempunctata was monitored by transfers of adults from the field to the laboratory at $25^{\circ} \mathrm{C}$. Diapause was completed in December-January, whereupon it was replaced by postdiapause quiescence that lasted until spring when, under the influence of temperature increasing above around $12^{\circ} \mathrm{C}$, the adults dispersed from hibernation sites to localities with aphids, where they fed and reproduced [6].

Whereas field observations indicate a univoltine cycle in central Greece, a tendency to multivoltinism was documented in C. septempunctata in this region, when four subsequent generations were reared in modified outdoor conditions [7]. The conditions were improved by shading of the rearing cages from direct insolation and continually providing surplus of suitable aphid prey.

3.2. Ceratomegilla undecimnotata (Schneider). Similar to $H$. convergens, the relative role of food and photoperiod in diapause regulation in C. undecimnotata is not yet clear enough, although the share of food/prey appears important.

The earlier studies on this Palaearctic species were undertaken in France and Czech Republic [6]. Detailed laboratory and field studies in central Greece [8] widened our knowledge of diapause in this species. The authors dissected 
the females of C. undecimnotata that were sampled from the field in mid-June. About $40-50 \%$ of nonreproductive females were recorded in the plain, while most females (70$100 \%$ in different years) were at the same time immature in aggregations on mountain summits, where they remained until spring. This should indicate a univoltine cycle. When, however, the beetles were provided with a surplus of aphids outdoors (under shading, but natural photoperiod), five subsequent generations were produced. With about 30\% of immature females in the first three generations, such diapause incidence was not far from the field records from the plain. These data indicate that C. undecimnotata populations from central Greece are heterogeneous as regards the induction of diapause. These findings are similar to $C$. septempunctata and $H$. convergens.

Samples from mountain tops were regularly transferred to laboratory $\left(25^{\circ} \mathrm{C}\right.$, long day $16 \mathrm{~L}: 8 \mathrm{D}$, prey surplus $)$. Females were activated under these conditions by tachytelic processes and laid eggs after a gradually shortened preoviposition period ( $92 \mathrm{~d}$ in July, $63 \mathrm{~d}$ in August, $20 \mathrm{~d}$ in September). This decrease in diapause intensity demonstrated the progress of diapause development by horotelic processes in the field.

All these results, similar to the French and Czech findings [6], indicate that C. undecimnotata is a long-day insect (long day is diapause preventing and not diapause inducing as assumed in the recent paper [8]). (The generic name Hippodamia used in [8] is not correct.)

3.3. Hippodamia convergens Guerin. In this common Nearctic aphidophagous ladybird, several possibilities of diapause induction were proposed by Hagen [9] for the plains of Northern California-and not much has been added later to his hypothesis. Originally, before the installation of irrigation systems, most individuals had an (obligatory ?) univoltine cycle (with a complex migration to mountains where enormous quantities of beetles aggregate for overwintering and are collected for biocontrol purposes). Later the Californian ladybird populations changed to multivoltine cycle, due to the high abundance of introduced aphids and are induced to diapause by photoperiod and temperature. However, diapause can still be nutritionally induced in a part of the population $[9,10]$. In the upper coastal plain of South Carolina, diapause in $H$. convergens is terminated in December/January after the transfer to temperatures $>15.5^{\circ} \mathrm{C}$, despite short days $12 \mathrm{~L}: 12 \mathrm{D}$ [11].

We need to know much more about the combined action of food and other factors in this species. Such studies have evidently begun with the analyses of the role of nutritional factors (nonaphid protein rich alternative food) in the arid conditions. In the Great Plains region in the central USA $H$. convergens is normally bivoltine, with obligate winter hibernation and facultative summer estivation which creates the possibility for additional generations when conditions permit. Various cases of nutritional regulation of reproductive diapause were analysed in females of $H$. convergens in these populations $[12,13]$. The importance of drinking sap on sunflower in the summer months in West Kansas was examined. Sunflower petioles and pollen as well as lepidopteran eggs were provided to the beetles collected in early June. While these females did not oviposit in the absence of protein food, feeding on eggs of Ephestia kuehniella followed by pollen enabled $66 \%$ of the females to lay viable eggs at a low rate of 6.6 eggs/day. The females, transferred on 14 August to essential aphid food (Schizaphis graminum), laid six times more eggs.

These experiments stressed the adaptive role of the life cycle in $H$. convergens in that it enables survival during arid summer conditions when there is a shortage of the essential food, aphids. In the absence of protein-rich food, the 1st generation can enter diapause. Another tactic could be to wait in a state of lowered metabolism (but less lowered than in diapause) for the reappearance of essential aphid food, relying meanwhile on alternate foods. Then a switch to intensive egg laying can be quick, as was shown by a short oviposition delay of only 4 or 6-9 days on essential prey $[12,13]$.

3.4. Harmonia axyridis (Pallas). After the very early Russian studies from Asia (see [6]) only two Japanese papers were published, dealing with diapause of this coccinellid from east Asia-before its invasion to America and Europe. In Japan this bivoltine long-day insect hibernates in diapause $[14,15]$ and uses the polyol myo-inositol to increase its coldhardiness [15].

After its arrival in Europe this invasive species was studied in South-Eastern France, Northern Italy, and Belgium and has become the most studied coccinellid. Facultative diapause of the multivoltine strain is induced by short-day photoperiod $12 \mathrm{~L}: 12 \mathrm{D}$ at $23^{\circ} \mathrm{C}$ and lasted $1-3$ months; eggs of Ephestia kuehniella were used as a suitable alternative food [16-19].

\section{Chrysomelidae}

4.1. Leptinotarsa decemlineata (Say). It was probably the first insect model for the detailed experimental study of adult diapause. Thanks to the intensive research by the team of Professor Jan de Wilde, Wageningen, The Netherlands, particularly the physiological/endocrinological aspects of diapause have been intensively investigated since the late 1950's [20]. These studies are reviewed in the important compendia $[1,2]$ and in the introduction of a paper by de Wilde's followers [21]. Research on the prolonged diapause in L. decemlineata and its dependence of soil types was focused by the team of Professor Raisa Ushatinskaya, Moscow, Russia [22].

The main facts on diapause regulation from the classic Dutch studies will be given here to make the reading of more recent studies below more easy. Diapause is induced by short-day photoperiod: $10 \mathrm{~L}: 14 \mathrm{D}$ at $25^{\circ} \mathrm{C}$ have been used in Wageningen and 16L:8D was the long-day photoperiod. Both larvae and adults are sensitive to induction [23]. 20$30 \%$ of beetles enter diapause under any photoperiod; thus a propensity to obligatory univoltinism is indicated, similar to the case of C. septempunctata, discussed above. Diapause development in L. decemlineata progressed well under any 
of three temperatures, 4,12 , and also $25^{\circ} \mathrm{C}$, that is, it does not need period of low temperatures for its completion (similar to quite a number of other insect species [3]). At $4{ }^{\circ} \mathrm{C}$ mortality was high ( $15 \%$ after $3 \mathrm{mo}, 50-70 \%$ after 6-7 mo), while it was $<10 \%$ at 12 and $25^{\circ} \mathrm{C}$. Diapause development was faster at 25 than $12^{\circ} \mathrm{C}$, and $50 \%$ of females spontaneously emerged from soil after 14 and $21 \mathrm{wk}$, respectively. Sensitivity to photoperiod is retained during diapause development at least to February: at this sensitive period, diapause can be terminated by only three long days. The females lose photoperiodic response for at least $5 \mathrm{wk}$ after the completion of diapause development, but the responsiveness is restored $3 \mathrm{wk}$ after diapause in a part of the population (recurrent photoperiodic response, discussed in Section 12). However, photoperiodic sensitivity is never lost completely, even after the completion of diapause it affects the rate of vitellogenesis and ovarian maturation.

Because of the importance of the Colorado potato beetle as pest, the primary insect defoliator of solanaceous crops in North America and Eurasia [24], research continues on different aspects. Flight incidence and duration in relation to mating was recorded by flight mills [25]. Mating has a pronounced effect on flight activity decreasing it in females, evidently because migration and reproduction interfere with each other, and increasing it in males - they may thus mate with females from different localities.

Oviposition and burrowing behavior (as contrasting characteristics of nondiapause versus diapause, resp.) were compared in 1st generation females along a $5^{\circ}$ latitudinal gradient, in six populations from North Dakota and Minnesota, USA, and Manitoba, Canada. Four locations were sampled in the Red River Valley region (between $49^{\circ} 49^{\prime} \mathrm{N}$ and $47^{\circ} 00^{\prime} \mathrm{N}$ ) and two in east central Minnesota $\left(45^{\circ} 20^{\prime} \mathrm{N}\right.$ and $\left.44^{\circ} 44^{\prime} \mathrm{N}\right)$. Different incidence of oviposition was recorded under long days in the RRV region (0-1\%) and in ECM samples (9-15\%). The authors conclude that L. decemlineata has the capability of becoming adapted to local environmental drivers, while retaining intrapopulation variability [26].

Some Colorado potato beetles enter prolonged $(>1 \mathrm{yr})$ dormancy, an event quite common in adults dormant in the soil, such as some curculionids discussed below. This phenomenon was studied earlier in Russian populations and those from Western United States, where a very high incidence $(22 \%)$ was recorded. M. J. Tauber and C. A. Tauber [24] studied its frequency in the Upstate New York in a 10-yr field study and recorded an average $2.04(0-72) \%$ in 12,607 beetles. They explain this relatively low incidence in North Eastern United States by the late arrival of $L$. decemlineata after the introduction of cultivated solanaceous crops. In Western United States, in contrast, the Colorado potato beetle commonly occurs on wild solanaceous host plants in drought-prone habitats.

Both the effect of age of potato foliage and temperature are important in the prediapause beetles [27]. The adults consumed older foliage at a faster rate, particularly at the higher temperature of $17^{\circ} \mathrm{C}$ (compared with $11.5^{\circ} \mathrm{C}$ ) and consumed $45 \%$ higher weight of leaves. It is assumed that there is a fixed requirement of accumulated reserves to achieve prediapause satiation. If the food is less rich in needed substances, larger amounts have to be consumed.

In populations from Central Europe $70-80 \%$ of reproducing females develop under $>15 \mathrm{~h}$ day length, while under $<14 \mathrm{~h}$ day length all beetles enter diapause [28]. In experiments the photoperiod of $12 \mathrm{~L}: 12 \mathrm{D}$ was used as short day, and 18L:6D as long day. The index of food conversion was 5.4 under long days, but 7.2 and 11.9 under short days (at 20 and $25^{\circ} \mathrm{C}$, resp.). Pupae were smaller under long days due to a greater loss of biomass during the prepupal stage that was almost twice as long as under short days.

The functional state of flight muscles was assessed by staining with commercially available (Sigma-Aldrich) tetrazolium salts; the color develops due to reduction of a colourless salt by mitochondrial enzymes [29].

The research on diapause of $L$. decemlineata continues also in the recent molecular biology age. In a study of gene expression patterns during the first 20 postemergence days in beetles programmed for diapause (at $8 \mathrm{~L}: 16 \mathrm{D}, 24^{\circ} \mathrm{C}$ ), that is, in prediapause phase, oxygen consumption was measured in this period. The respiration rate increased from $0.4 \mathrm{~mL} / \mathrm{g} / \mathrm{h}$ on day 1 to $1.1 \mathrm{~mL} / \mathrm{g} / \mathrm{h}$ on day 4 , and after a plateau between days 4 and 7 the oxygen consumption decreased to $0.08 \mathrm{~mL} / \mathrm{g} / \mathrm{h}$ on day 15 . The $\mathrm{CO}_{2}$ production followed the same curve, with an additional conspicuous peak on day 7. Among the clones of genes isolated, elevated levels of expression of the glycine-rich transcripts (that function in structural support of insect cuticle) persisted for four days longer in diapause-programmed beetles, compared with nondiapause adults. The differentially regulated genes were downregulated between days 13 and 20, that is, at the end of prediapause when the metabolic rate was already much decreased [30].

The series of papers by Yocum and coauthors has continued by a recent one [31]. Prediapause and diapause phases of development are well marked by expression of genes in laboratory reared adults. However, it is much less clear in field collected adults, evidently due to the polyphenic character of diapause, mentioned earlier. The authors conclude that this property contributes to the status of $L$. decemlineata as a "superpest" of potatoes [31]. This characteristic is similar to that in C. septempunctata, where also the plastic character of adult diapause is obviously associated with the "success" of the species [32].

4.2. Colaphellus bowringi Baly. A complex analysis of diapause regulation was conducted by Professor Xue and coauthors in a series of recent papers. The cabbage beetle, $C$. bowringi, is a pest of cruciferous vegetables in mountain areas of Jiangxi Province, China. There are four generations per year, one in spring and three in autumn. The beetle estivates and hibernates as adult in the soil. A life-cycle polymorphism was reported by Xue and Zhang 20 yrs earlier (for an English summary of that paper published in Chinese, see [33]). Although the adults enter diapause at the same time, they differ much in diapause duration (several monthstwo yrs) and thus they expressed heterogeneous voltinism. Without regard to diapause induction and duration, the post-diapause beetles emerge from soil either between late 
February and early April, or between mid-August and early October.

C. bowringi is a short-day species (i.e., long days induce diapause), but the photoperiodic response is strongly affected by temperature. High temperatures enhance the diapause-averting effects of short days and suppress the diapause-inducing effects of long days. Diapause incidence is $100 \%$ at $<20^{\circ} \mathrm{C}$ at any photoperiod. Photoperiod plays a relatively small role in diapause induction; short days can prevent diapause only at temperatures above $20^{\circ} \mathrm{C}$. The mechanisms ruling the complex seasonal life-cycle in $C$. bowringi are well explained by experimental results [33]. It is probably the first documented case of summer diapause induction by low temperature instead of high temperature. Diapause is entered by early-emerging individuals in April. The authors suggest that the photoperiodic and temperature controls of diapause induction have a different genetic basis.

Experiments on the effect of thermoperiods on diapause induction in C. bowringi showed again the importance of temperature, particularly during the photophase [34].

Other detailed experiments documented an important effect of host plants on diapause incidence in C. bowringi [35]. The highest incidence of diapause was caused by feeding on radish (Raphanus sativus) and the dark green variety of Chinese cabbage: the lowest incidence was obtained by feeding on the yellow-green variety of Chinese cabbage with thin leaves. Most adults entered diapause on mature and aged leaves. Diapause incidence was affected by host plants only within a certain range of photoperiods and temperatures; it was best manifested at $25^{\circ} \mathrm{C}$ and $13 \mathrm{~L}: 11 \mathrm{D}$. Regardless of host plants, all adults entered diapause at $20^{\circ} \mathrm{C}$ or at $16 \mathrm{~L}: 8 \mathrm{D}$, as indicated in the earlier papers.

There is no negative tradeoff between diapause duration and several parameters of performance in adults after diapause: the body weight, longevity, and fecundity of beetles with the longer diapause duration of 21 mo were higher than those with the shorter duration of 5, 11, and $17 \mathrm{mo}$ [36].

Crossing a high diapause strain with a laboratory selected nondiapause strain showed that diapause capability is inherited in an incomplete dominant manner; maternal inheritance of diapause induction is stronger than paternal inheritance [37].

4.3. Zygogramma bicolorata Pallister. This chrysomelid was successfully introduced to Jammu and Kashmir, India for biological control of carrot weed, Parthenium hysterophorus L. Adults enter diapause from August to December with a peak in late November. They burrow into soil and are dormant about $1-3 \mathrm{~cm}$ bellow the surface. The incidence of burrowing adults increases with soil moisture and is higher in silty soil $(47 \%)$ than in sandy soil $(24 \%)$. Diapause is facultative as nondiapausing adults breed in winter under laboratory conditions. The beetles become active in March and, after having defoliated their host plants in an area, they disperse and need not be introduced to other areas. By treating the newly emerged beetles with human insulin $(5: \mathrm{g})$ the incidence of diapause was lowered and the fecundity increased [38].
In a population from Jabalpur, India, $64 \%$ of beetles entered diapause at $26^{\circ} \mathrm{C}$ and photoperiod was not important. Storage of females at $10^{\circ} \mathrm{C}$ for 6 mo did not lower their fecundity [39].

4.4. Plagiodera versicolora Laicharting. This is a species with facultative diapause that feeds on several species of willows. Experimental populations from the region of the river Ishikari $\left(43^{\circ} \mathrm{N}\right.$, Hokkaido, Japan) had both univoltine and bivoltine life-cycles and were most abundant on Salix sachalinensis Fr.Smidt.

All females entered diapause at $10 \mathrm{~L}: 14 \mathrm{D}$, but a rather high incidence also was recorded at 16L:8D (68\% with a range of $40-100 \%$ ) [40]. These are evidently results from rearing beetles on leaves of mixed quality, as only $10 \%$ diapause was reported in the 1st generation reared on 2-22 July on young leaves [41]. Diapause induced under short days of $10 \mathrm{~L}: 14 \mathrm{D}$ at $22^{\circ} \mathrm{C}$ was terminated by long days of $16 \mathrm{~L}: 8 \mathrm{D}$ at $22^{\circ} \mathrm{C}[42]$.

Later the effect of photoperiod and temperature (16L : 8D and $20^{\circ} \mathrm{C}$ in the laboratory) was experimentally isolated from the effect of seasonally changing quality of host-plant leaves [41]. While the abiotic laboratory conditions were kept constant, the leaves of $S$. sachalinensis were collected in the field and thus gradually more mature leaves were provided. The reproductive parameters declined in the 2 nd and 3rd generations, in comparison with the 1st generation. Diapause incidence increased from 10 to $60 \%$, the preoviposition period increased from about 9 to $16 \%$, and the fecundity during the first 10 days of the egg laying period decreased from about 50 to 18 eggs per female. The authors thus documented the effect of host plant age and suggested that the combination of both day length and host-plant conditions cuing diapause is adaptive [41].

4.5. Galerucella calmariensis $L$. It was introduced to the United States for the biological control of purple loosestrife (Lythrum salicaria L.). The adults undergo a facultative reproductive diapause (the paper's abstract mentions obligatory diapause by mistake) during summer, autumn, and winter. Diapause can be averted by long days of $16 \mathrm{~L}: 8 \mathrm{D}$ and induced by $8 \mathrm{~L}: 16 \mathrm{D}$. Adults are responsive to diapauseinducing photoperiods. The authors failed to isolate the cultures efficiently from insolation with white tissue tents as the natural photoperiod produced a seasonal effect; in early summer the ovaries matured better [43].

4.6. Crioceris sp. This undescribed chrysomelid species was studied in the Western Cape Province, South Africa $\left(34^{\circ} 35^{\prime} \mathrm{S}\right)$ as a promising biocontrol agent of bridal creeper (Asparagus asparagoides (L.) W. Wight) with the intention to introduce it to Australia.

The majority of fully developed adults remain inside cocoons in soil for various periods of summer diapause. Field observations suggest that rainfall might be the cue for termination of diapause or dormancy. The effect of wetting was demonstrated in the laboratory. Only $29 \%(n=135)$ adults emerged from dry cocoons at $20^{\circ} \mathrm{C}$ within 76 days. 
This proportion was substantially increased by wetting, and even more by repeated wetting.

No research addressed the mechanism of diapause regulation by physical and biotic environmental factors, although larvae were reared successfully to pupation in soil at 15 and $20^{\circ} \mathrm{C}[44]$.

\section{Bruchidae}

5.1. Callosobruchus subinnotatus (PIC). It is a major pest of stored bambara groundnut, Vigna subterranea (L.) Verdcourt in sub-Saharan West Africa. Adult polymorphism was described in this bruchid, similar to that of some other species of the family, particularly C. maculatus (Fabricius), that was the model insect for a series of classic ecological studies by Professor Syunro Utida from Kyoto University, Japan, in the years 1954-1981. The terms for the two polyphenic forms, used in the earlier C. maculatus studies, were also used here although they do not seem very adequate: "active" and normal adults. While the normal adults have a high fecundity, low longevity, and lower tendency to dispersal, the "active" phase shows opposite qualities. Dissections reveal immature ovaries and male gonads, so we might consider this suspension of reproduction an adult diapause or at least a diapause-like phenomenon. Although high population density was suggested in several Utida's articles to be the factor responsible for the development of "active" form, no attempts have been made to address this influence in C. subinnotatus [45].

Another congeneric bruchid, Callosobruchus rhodesianus (Pic), suffering from strong competition by C. maculatus on cowpea, Vigna unguiculata (Walp.) in Togo, Africa, reproductive diapause was recorded [46] in a part of population.

5.2. Bruchidius dorsalis Fahraeus. This multivoltine seedeater occurs in Central and Southern Japan. Females oviposit on seedpods of the Japanese honey locust, Gleditsia japonica. Newly matured seeds are available from August to autumn, but the females may use also dry, hardened seeds; thus host seeds can be utilized almost the whole year.

In contrast to most insect species, in warmer regions $B$. dorsalis enters diapause in different developmental stages: final larval instars and adults. Even nondiapausing early instars may overwinter [47]. In Sagamihara $\left(35^{\circ} 34^{\prime} \mathrm{N}\right) 3$ to 4 generations develop per year. Some autumnal adults produce the new generation before winter, while another part of the population overwinters before spring reproduction. Diapause is induced by short days and the first five days after adult emergence are sensitive to diapause-inducing factors.. Diapause incidence was higher and the critical photophase longer in cooler regions $[48,49]$.

\section{Curculionidae}

6.1. Curculio nucum (L.). This specialist of hazelnut trees has an obligate 2 -yr cycle in France $\left(45^{\circ} 46^{\prime} \mathrm{N}, 420 \mathrm{~m}\right.$ a.s.l.) with one larval diapause in winter, pupation and ecdysis of adults (in soil) the next summer, and in the 2 nd winter adult diapause. In spring the overwintered adults emerge from the soil in April and appear on trees from May to early July [50]. Early emergence from the soil enables females to oviposit in nuts before they fully harden. As they cannot penetrate the mature nut, they must oviposit before July.

Females lose about $8.5 \%$ of their weight during overwintering, but their lipid content does not decrease. Thus the authors suppose that females use lipids accumulated during the larval stage for egg production and obtain other nutrients from adult feeding. Evolutionary forces triggering the obligate 2-yr cycle are discussed [50].

6.2. Exapion ulicis (Forster). This univoltine species consumes the seed of gorse, Ulex europaeus, that has peak fruiting in spring and was introduced to some countries for its biological control. Adults lay eggs in spring into young green pods where the larvae develop adults feed on leaves and flowers of gorse and then diapause in autumn and winter. In winter the beetles stay on branches and are able to resist cold. In Brittany, France, the species was studied together with E. lemovicinum (Hoffmann), a species that overwinters in the larval stage, to understand its cold-hardiness. E. ulicis adults are freezing intolerant, but exhibit a low supercooling point of $-17^{\circ} \mathrm{C}$. The regulation of diapause induction and termination was not studied [51].

\section{Carabidae}

7.1. Nebria salina Fairmaire and Laboulbene. This species is common in unproductive habitats, such as sand dunes and upland grasslands. This short-day insect is an autumn breeder that enters a summer diapause. Females require at least two months of exposure to short-day photoperiods of $<12 \mathrm{~L}: 12 \mathrm{D}$. Under long days of $18 \mathrm{~L}: 6 \mathrm{D}$ the ovaries do not mature. Still shorter days of $6 \mathrm{~L}: 18 \mathrm{D}$ stimulate better growth of ovaries. The males matured after two months irrespective of photoperiod.

In the field (Hamsterley, County Durham, UK) the main activity of $N$. salina was concentrated in September [52]. Thus, the life cycle of this species resembles the congeneric autumn breeder Nebria brevicollis, where diapause was studied in the 80 's by Hengeveld and Loreau (quoted in Telfer and Butterfield [52]).

7.2. Carabus yaconinus. When the authors transferred this spring breeder from the field to laboratory experimental photoperiods, the beetles showed a long-day photoperiodic response in autumn and early winter. In the course of winter the response was gradually lost, so that in late April the ovaries of females matured both in short and long days [53]. However, in summer the photoperiodic response resumed again. Thus C. yaconinus appears to be another case of recurrent photoperiodic response that was revealed for the first time in a pentatomid bug Aelia acuminata [54] and recorded later also in L. decemlineata and C. septempunctata (see above). 


\section{Silphidae}

8.1. Nicrophorus nepalensis. This subtropical short-day breeding carrion beetle that occurs in Taiwan $\left(24^{\circ} 45^{\prime} \mathrm{N}\right.$, $745 \mathrm{~m}$ a.s.l.) is active mainly in early spring (FebruaryMay) and also in autumn (October-November). Reproduction is best promoted at $20^{\circ} \mathrm{C}$ and a photoperiod of $12.5 \mathrm{~L}: 11.5 \mathrm{D}$, but only in the presence of carrion, whereupon oviposition starts after 2 weeks. At a lower temperature of $15^{\circ} \mathrm{C}$ and $11 \mathrm{~L}: 13 \mathrm{D}$, maturation is slower, so that the oviposition begins after about 9 weeks. In contrast, longer days (14L:10D) prevent oviposition at $25^{\circ} \mathrm{C}$, but enable oviposition of $45-50 \%$ of females at $20^{\circ} \mathrm{C}$. Summer diapause is an efficient adaptation as the development of offspring on carrion in summer would suffer from competition with more quickly developing dipteran larvae on quickly decomposing dead animals [55].

\section{Scolytidae}

9.1. Ips typographus $L$. The number of generations varies in different countries, similar to other insect species. Flight parameters were studied in young beetles from five populations: one in Denmark $\left(56^{\circ} 51^{\prime} \mathrm{N}\right)$ and four in Sweden (between $57^{\circ} 40^{\prime} \mathrm{N}$ and $62^{\circ} 51^{\prime} \mathrm{N}$ ). The flight propensity of beetles that emerged in the period 34-80 days was tested and those flying less than 100 s ("non-fliers") were found by dissection to be in diapause with undeveloped ovaries and large fat reserves. The frequency of such beetles increased with increasing latitude from 35 to $70 \%$. While "fliers" migrate to find a breeding site, diapausing "non-fliers" often overwinter on the ground beneath the brood tree [56].

In a Central European population, diapause was induced by $<16 \mathrm{~L}: 8 \mathrm{D}$ at $20^{\circ} \mathrm{C}$ and the critical photoperiod $(50 \%$ diapause incidence) was $14.7 \mathrm{~L}: 9.3 \mathrm{D}$. Temperature of $>23^{\circ} \mathrm{C}$ prevented diapause even at 12L:12D. Neither gonads nor flight muscles matured in diapausing adults. Overwintering adults, shown to be in diapause by their response to photoperiod, reproduced at the long-day photoperiod of 18L: $6 \mathrm{D}$ but not at $12 \mathrm{~L}: 12 \mathrm{D}$ when transferred in October from the forest to laboratory $20^{\circ} \mathrm{C}$ [57].

\section{Scarabaeidae}

10.1. Dasylepida ishigakiensis Niijima and Kinoshita. This "white grub" is a serious pest of sugarcane on Okinawa Islands, Japan. It is the only scarabaeid beetle in which the regulation of adult diapause has been studied. Both larvae and adults of this subtropical beetle undergo diapause in a semivoltine (2-yr) life cycle. Adults emerge from pupae in the soil and stay there for about two months. This delayed emergence from the soil cannot be related to synchronization with food, because the adults have degenerated mouthparts and do not feed. The beetles begin to leave the soil in late autumn when cooler temperatures are favorable for mating. Sexual maturation in the laboratory is suppressed at temperatures of $25-30^{\circ} \mathrm{C}$, but proceeds well at $15-20^{\circ} \mathrm{C}$. Photoperiod does not seem to act in diapause regulation [58].

\section{Endomychidae}

11.1. Stenotarsus subtilis (=rotundus) Arrow. S. subtilis provides a case of tropical diapause that was studied in Panama $[59,60]$. This beetle forms large aggregations for a long dormancy, comprising 6 months of the wet season and 4 months of the dry season. Breeding sites, food, and diapauseinducing factors all remain unknown. Experiments with beetles collected from aggregations revealed the role of environmental factors in diapause development. Although in Panama $\left(9^{\circ} \mathrm{N}\right)$ the difference between the longest and shortest day is only $1 \mathrm{~h}$, increasing day length from March onward stimulates weak development of corpora allata, primary oocytes, and flight muscles that had remained resorbed for about 6 months. Mating and dispersal coincide with the onset of rains in late April. Two-month exposures to contrasting humidities revealed that higher humidity also stimulates development of the aforementioned organs [59, $60]$.

\section{Concluding Remarks}

It is almost impossible to make general conclusions from the recent data given above on the diapause of beetles. There are at least two obstacles: (1) diapause is a seasonal adaptation (see the Introduction) and it apparently evolved independently in individual species under specific environmental selective pressures that ultimately result in a genetic basis. Diapause of individual species/populations is thus intrinsically diversified-and inherently resists generalization. (2) The conditions for reasonable comparisons are further aggravated by diverse research protocols that have been employed by individual researchers either arbitrarily or under various technical constraints. Even in the case of currently studied species (that often are economically important), such as some chrysomelids, curculionids, or coccinellids, research analyses have often remained incomplete. This is still even more true for fragmentary studies some of which are included here only to show the wide range of records.

In spite of these difficulties, we may try to deduce some general features (that may apply to other insect orders as well). No particular break of the classic paradigms was made in the recent papers. They rather were further corroborated and extended. The most general, and the most studied, is the signaling function of photoperiod, often modified by effects of temperature and food that announces seasonal transitions with astronomical precision. In particular populations, photoperiodic response is always adapted to geographic latitude, as has been shown above best in L. decemlineata populations originating from locations separated by about $5^{\circ}$ latitude. In some common and widely studied species, such as the Nearctic coccinellid $H$. convergens, the evidence of the photoperiodic regulation has still remained rather scarce.

An effect of food quality implicated in several of the discussed species. The difference of old versus young leaves is well documented in L. decemlineata and C. bowringi; the effect of alternative food (e.g., pollen) versus essential aphid species has been studied in detail in C. septempunctata [6] 
and $H$. convergens $[12,13]$. In the ladybird Ceratomegilla undecimnotata (Schneider) the physiological age of host plant can even act through the aphid prey, as reported in the 70's see [61] (see also) [6].

The effect of population density has remained rather neglected in the beetles discussed here. The exceptions are early articles on the bruchid C. maculatus, where the effect was recorded long ago by Professor Utida, and the observations on C. subinnotatus.

As mentioned above, diapause adaptations are very plastic in response to selection. Similar to changes in photoperiod, beetles can adapt quite quickly to environmental changes associated with changes in food supply. Thus, for example, introduction of irrigation in arid areas led to the establishment of prey in two coccinellids, $H$. convergens in California and Chilocorus bipustulatus L. in Israel, and thereafter to changes in their life cycles [6].

It is worthwhile to speculate about a hierarchy of individual factors governing diapause regulation. The basic driver is usually photoperiodic response to the precise annual astronomical repetition of day length. We may assume that less rigid reactions to less predictable environmental changes in food availability and quality, and other factors such as temperature, humidity, and population density, can be superimposed. The archetypal nutritive factor is "prepared to enter the game" in the case of unpredictable events affecting prey abundance-and this is facilitated by phenotypic plasticity.

Polyphenic character of diapause is a very important feature in C. septempunctata and L. decemlineata, but it has been found also in other Coleoptera and in insects generally: populations are heterogeneous as to voltinism tendencies. For populations with mixed uni- and polyvoltine tendencies we might envisage a scenario which combines plasticity with resilience. One aspect of the life-cycle strategies is the "safety" ("insurance") factor of the univoltine trait which is permanently perpetuated in the gene pool and maintained (i.e., not selected out) despite the frequent momentary occurrence of conditions favourable for the production of an additional generation, since these transitory conditions are unreliable in the long run. However, polygenes facilitate population responses to changes in the environment. If there is a promising improvement they may "open the gate" for intermittent multivoltine development, that may be more or less appropriate to capitalize on transitory environmental improvement. The system remains resilient because the univoltine trait is maintained quite intensively. This scenario is adequate for C. septempunctata and perhaps also $L$. decemlineata living in temperate regions/climate. In different climatic areas, the regulation of voltinism can differ.

\section{References}

[1] H. V. Danks, Insect Dormancy: An Ecological Perspective, Biological Survey of Canada (Terrestrial Arthropods), Ottawa, Canada, 1987.

[2] M. J. Tauber, C. A. Tauber, and S. Masaki, Seasonal Adaptations of Insects, Oxford University Press, Oxford, UK, 1986.
[3] I. Hodek and M. Hodkova, "Multiple role of temperature during insect diapause: a review," Entomologia Experimentalis et Applicata, vol. 49, no. 1-2, pp. 153-165, 1988.

[4] S. Masaki, "Summer diapause," Annual Review of Entomology, vol. 25, pp. 1-25, 1980.

[5] M. W. Phoofolo and J. J. Obrycki, "Demographic analysis of reproduction in Nearctic and Palearctic populations of Coccinella septempunctata and Propylea quatuordecimpunctata," BioControl, vol. 45, no. 1, pp. 25-43, 2000.

[6] I. Hodek, "Dormancy," in Ecology of Coccinellidae, I. Hodek and A. Honek, Eds., pp. 239-318, Kluwer Academic, The Hague, The Netherlands, 1996.

[7] P. Katsoyannos, D. C. Kontodimas, and G. Stathas, "Summer diapause and winter quiescence of Coccinella septempunctata (Col. Coccinellidae) in central Greece," Entomophaga, vol. 42, no. 4, pp. 483-491, 1997.

[8] P. Katsoyannos, D. C. Kontodimas, and G. Stathas, "Summer diapause and winter quiescence of Hippodamia undecimnotata (Coleoptera: Coccinellidae) in central Greece," European Journal of Entomology, vol. 102, no. 3, pp. 453-457, 2005.

[9] K. S. Hagen, "Biology and ecology of Coccinellidae," Annual Review of Entomology, vol. 7, pp. 289-326, 1962.

[10] J. R. Davis and R. L. Kirkland, "Physiological and environmental factors related to the dispersal flight of the convergent lady beetle, Hippodamia convergens (Guerin-Meneville)," Journal of the Kansas Entomological Society, vol. 55, pp. 187-196, 1982.

[11] S. H. Roach and W. M. Thomas, "Overwintering and spring emergence of three coccinellid species in the coastal plain of South Carolina," Environmental Entomology, vol. 20, pp. 540544, 1991.

[12] J. P. Michaud and J. A. Qureshi, "Induction of reproductive diapause in Hippodamia convergens (Coleoptera: Coccinellidae) hinges on prey quality and availability," European Journal of Entomology, vol. 102, no. 3, pp. 483-487, 2005.

[13] J. P. Michaud and J. A. Qureshi, "Reproductive diapause in Hippodamia convergens (Coleoptera: Coccinellidae) and its life history consequences," Biological Control, vol. 39, no. 2, pp. 193-200, 2006.

[14] H. Sakurai, S. Takeda, and T. Kawai, "Diapause regulation in the lady beetle, Harmonia axyridis," in Ecology and Effectiveness of Aphidophaga, E. Niemczyk and A. F. G. Dixon, Eds., pp. 67-70, SPB Academic, The Hague, The Netherlands, 1988.

[15] M. Watanabe, "Cold tolerance and myo-inositol accumulation in overwintering adults of a lady beetle, Harmonia axyridis (Coleoptera: Coccinellidae)," European Journal of Entomology, vol. 99, no. 1, pp. 5-9, 2002.

[16] P. Ongagna and G. Iperti, "Influence de la temperature et de la photoperiode chez Harmonia axyridis pall.(Col., Coccinellidae): obtention d'adultes rapidement feconds ou en dormance," Journal of Applied Entomology, vol. 117, pp. 314317, 1994.

[17] G. Iperti and E. Bertand, "Hibernation of Harmonia axyridis (Coleoptera: Coccinellidae) in south-eastern France," Acta Societatis Zoologicae Bohemicae, vol. 65, pp. 207-210, 2001.

[18] G. G. Bazzocchi, A. Lanzoni, G. Accinelli, and G. Burgio, "Overwintering, phenology and fecundity of Harmonia axyridis in comparison with native coccinellid species in Italy," BioControl, vol. 49, no. 3, pp. 245-260, 2004.

[19] N. Berkvens, J. Bonte, D. Berkvens, L. Tirry, and P. De Clercq, "Influence of diet and photoperiod on development and reproduction of European populations of Harmonia axyridis (Pallas) (Coleoptera: Coccinellidae)," BioControl, vol. 53, no. 1, pp. 211-221, 2008. 
[20] J. D. Wilde, C. S. Duintjer, and L. Mook, "Physiology of diapause in the adult Colorado beetle (Leptinotarsa decemlineata Say). The photoperiod as a controlling factor," Journal of Insect Physiology, vol. 3, no. 2, pp. 75-85, 1959.

[21] K. S. Lefevere and C. A. D. De Kort, "Adult diapause in the Colorado potato beetle, Leptinotarsa decemlineata: effects of external factors on maintenance, termination and postdiapause development," Physiological Entomology, vol. 14, no. 3, pp. 299-308, 1989.

[22] R. S. Ushatinskaya, "Seasonal migration of adult Leptinotarsa decemlineata (Coleoptera) in different types of soil and physiological variations of individuals in hibernating populations," Pedobiology, vol. 18, pp. 120-126, 1978.

[23] I. Hodek, "Sensitivity of larvae to photoperiods controlling the adult diapause of two insects," Journal of Insect Physiology, vol. 17, no. 2, pp. 205-216, 1971.

[24] M. J. Tauber and C. A. Tauber, "Prolonged dormancy in Leptinotarsa decemlineata (Coleoptera: Chrysomelidae): a tenyear field study with implications for crop rotation," Environmental Entomology, vol. 31, no. 3, pp. 499-504, 2002.

[25] A. V. Alyokhin and D. N. Ferro, "Reproduction and dispersal of summer-generation colorado potato beetle (Coleoptera: Chrysomelidae)," Environmental Entomology, vol. 28, no. 3, pp. 425-430, 1999.

[26] D. G. Senanayake, E. B. Radcliffe, and N. J. Holliday, "Oviposition and diapause behavior in Colorado potato beetle (Coleoptera: Chrysomelidae) populations from east central Minnesota and the Valley of the Red River of the North," Environmental Entomology, vol. 29, no. 6, pp. 1123-1132, 2000.

[27] C. Noronha and C. Cloutier, "Effects of potato foliage age and temperature regime on prediapause Colorado potato beetle Leptinotarsa decemlineata(Coleoptera: Chrysomelidae)," Environmental Entomology, vol. 35, no. 3, pp. 590-599, 2006.

[28] P. Dolezal, O. Habustova, and F. Sehnal, "Effects of photoperiod and temperature on the rate of larval development, food conversion efficiency, and imaginal diapause in Leptinotarsa decemlineata," Journal of Insect Physiology, vol. 53, no. 8, pp. 849-857, 2007.

[29] P. Dolezal and F. Sehnal, "A simple method for the detection of imaginal diapause in beetles," Journal of Applied Entomology, vol. 131, no. 3, pp. 221-223, 2007.

[30] G. D. Yocum, J. P. Rinehart, A. Chirumamilla-Chapara, and M. L. Larson, "Characterization of gene expression patterns during the initiation and maintenance phases of diapause in the Colorado potato beetle, Leptinotarsa decemlineata," Journal of Insect Physiology, vol. 55, no. 1, pp. 32-39, 2009.

[31] G. D. Yocum, J. P. Rinehart, and M. L. Larson, "Monitoring diapause development in the Colorado potato beetle, Leptinotarsa decemlineata, under field conditions using molecular biomarkers," Journal of Insect Physiology, vol. 57, pp. 645-665, 2011.

[32] I. Hodek and J.-P. Michaud, "Why is Coccinella septempunctata so successful? (A point-of-view)," European Journal of Entomology, vol. 105, no. 1, pp. 1-12, 2008.

[33] F. S. Xue, H. R. Spieth, L. Aiqing, and H. Ai, "The role of photoperiod and temperature in determination of summer and winter diapause in the cabbage beetle, Colaphellus bowringi (Coleoptera: Chrysomelidae)," Journal of Insect Physiology, vol. 48, no. 3, pp. 279-286, 2002.

[34] X. P. Wang, F. S. Xue, F. Ge, C. A. Zhou, and L. S. You, "Effects of thermoperiods on diapause induction in the cabbage beetle, Colaphellus bowringi (Coleoptera: Chrysomelidae)," Physiological Entomology, vol. 29, no. 5, pp. 419-425, 2004.
[35] X. P. Wang, F. Ge, and F. S. Xue, "Host plant mediation of diapause induction in the cabbage beetle, Colaphellus bowringi Baly (Coleoptera: Chrysomelidae)," Insect Science, vol. 13, pp. 189-193, 2006.

[36] X. T. Wei, Y. C. Zhou, H. J. Xiao, X. P. Wang, Z. M. Bao, and F. S. Xue, "Relationship between the natural duration of diapause and post-diapause reproduction in the cabbage beetle, Colaphellus bowringi (Coleoptera: Chrysomelidae)," European Journal of Entomology, vol. 107, no. 3, pp. 337-340, 2010.

[37] X. J. Kuang, J. Xu, Q. W. Xia, H. M. He, and F. S. Xue, "Inheritance of the photoperiodic response controlling imaginal summer diapause in the cabbage beetle, Colaphellus bowringi," Journal of Insect Physiology, vol. 57, pp. 614-619, 2011.

[38] R. K. Gupta, S. Gupta, K. Bali, and K. Srivastava, "Enhancing bio-suppression of Parthenium hysterophorus L.: diapause in Zygogramma bicolorata Pallister and its manipulation through insulin-like peptides (ILPs)," Journal of Asia-Pacific Entomology, vol. 13, no. 4, pp. 303-308, 2010.

[39] Sushilkumar and P. Ray, "Activity enhancement of Zygogramma bicolorata, a biocontrol agent of parthenium hysterophorus, by temperature regulated diapause aversion," Biocontrol Science and Technology, vol. 20, no. 9, pp. 903-908, 2010.

[40] M. Ishihara, "Effect of variation in photoperiodic response on diapause induction and developmental time in the willow leaf beetle, Plagiodera versicolora," Entomologia Experimentalis et Applicata, vol. 96, no. 1, pp. 27-32, 2000.

[41] M. Ishihara and T. Ohgushi, "Reproductive inactivity and prolonged developmental time induced by seasonal decline in host plant quality in the willow leaf beetle Plagiodera versicolora (Coleoptera: Chrysomelidae)," Environmental Entomology, vol. 35, no. 2, pp. 524-530, 2006.

[42] M. Ishihara and T. Hayashi, "Photoperiodic induction and termination of adult diapause in the willow leaf beetle, Plagiodera versicolora, (Coleoptera: Chrysomelidae)," Entomological Science, vol. 3, pp. 439-441, 2000.

[43] R. A. M. Velarde, R. N. Wiedenmann, and D. J. Voegtlin, "Influence of photoperiod on the overwintering induction of Galerucella calmariensis L," BioControl, vol. 47, no. 5, pp. 587601, 2002.

[44] A. B. R. Witt and P. B. Edwards, "Aspects of the biology, distribution, and host range of Crioceris sp. (Col.: Chrysomelidae: Criocerinae), a potential biological control agent for Asparagus asparagoides in Australia," Biological Control, vol. 23, no. 1, pp. 56-63, 2002.

[45] J. H. Appleby and P. F. Credland, "Bionomics and polymorphism in Callosobruchus subinnotatus (Coleoptera: Bruchidae)," Bulletin of Entomological Research, vol. 91, no. 4, pp. 235-244, 2001.

[46] K. Amevoin, I. A. Glitho, J. P. Monge, and J. Huignard, "Why Callosobruchus rhodesianus causes limited damage during storage of cowpea seeds in a tropical humid zone in Togo," Entomologia Experimentalis et Applicata, vol. 116, no. 3, pp. 175-182, 2005.

[47] H. Kurota and M. Shimada, "Geographical variation in the seasonal population dynamics of Bruchidius dorsalis (Coleoptera: Bruchidae): constraints of temperature and host plant phenology," Environmental Entomology, vol. 31, no. 3, pp. 469-475, 2002.

[48] H. Kurota and M. Shimada, "Photoperiod-dependent adult diapause within a geographical cline in the multivoltine 
bruchid Bruchidius dorsalis," Entomologia Experimentalis et Applicata, vol. 106, no. 3, pp. 177-185, 2003.

[49] H. Kurota and M. Shimada, "Over-wintering stage polymorphism of a bruchine beetle: geographical variation in optimal diapause strategy," Ecological Entomology, vol. 32, no. 6, pp. 722-731, 2007.

[50] M. C. Bel-Venner, N. Mondy, F. Arthaud et al., "Ecophysiological attributes of adult overwintering in insects: insights from a field study of the nut weevil, Curculio nucum," Physiological Entomology, vol. 34, no. 1, pp. 61-70, 2009.

[51] M. Barat, P. Vernon, M. Tarayre, and A. Atlan, "Overwintering strategy of two weevils infesting three gorse species: when cold hardiness meets plant-insect interactions," Journal of Insect Physiology, vol. 56, no. 2, pp. 170-177, 2010.

[52] G. Telfer and J. E. L. Butterfield, "The control of reproductive diapause in Nebria salina (Coleoptera: Carabidae)," Ecological Entomology, vol. 29, no. 4, pp. 482-487, 2004.

[53] Y. Shintani and H. Numata, "Adaptive significance of the recurrent photoperiodic response in a spring-breeding carabid beetle, Carabus yaconinus," Entomological Science, vol. 13, no. 4, pp. 367-374, 2010.

[54] I. Hodek, "Sensitivity to photoperiod in Aelia acuminata (L.) after adult diapause," Oecologia, vol. 6, no. 2, pp. 152-155, 1971.

[55] W. Hwang and S. F. Shiao, "Dormancy and the influence of photoperiod and temperature on sexual maturity in Nicrophorus nepalensis (Coleoptera: Silphidae)," Insect Science, vol. 18, pp. 225-233, 2011.

[56] E. Forsse, "Flight propensity and diapause incidence in five populations of the bark beetle Ips typographus in Scandinavia," Entomologia Experimentalis et Applicata, vol. 61, no. 1, pp. 5357, 1991.

[57] P. Dolezal and F. Sehnal, "Effects of photoperiod and temperature on the development and diapause of the bark beetle Ips typographus," Journal of Applied Entomology, vol. 131, pp. 165173, 2007.

[58] S. Tanaka, F. Yukuhiro, H. Yasui, M. Fukaya, T. Akino, and S. Wakamura, "Presence of larval and adult diapauses in a subtropical scarab beetle: graded thermal response for synchronized sexual maturation and reproduction," Physiological Entomology, vol. 33, no. 4, pp. 334-345, 2008.

[59] S. Tanaka, "The role of moisture in the control of diapause, mating and aggregation in a tropical insect," Entomological Science, vol. 3, pp. 147-155, 2000.

[60] I. Hodek, "Role of water and moisture in diapause development (A review)," European Journal of Entomology, vol. 100, pp. 223-232, 2003.

[61] F. Rolley, I. Hodek, and G. Iperti, "Influence de la nouriture aphidienne (selon l'age de la plante-hote a partir de laquelle les pucerons se multiplient) sur l'induction de la dormance chez Semiadalia undecimnotata Schn. (Coleoptera: Coccinellidae)," Annales de Zoologie_Ecologie Animale, vol. 6, pp. 53-60, 1974. 

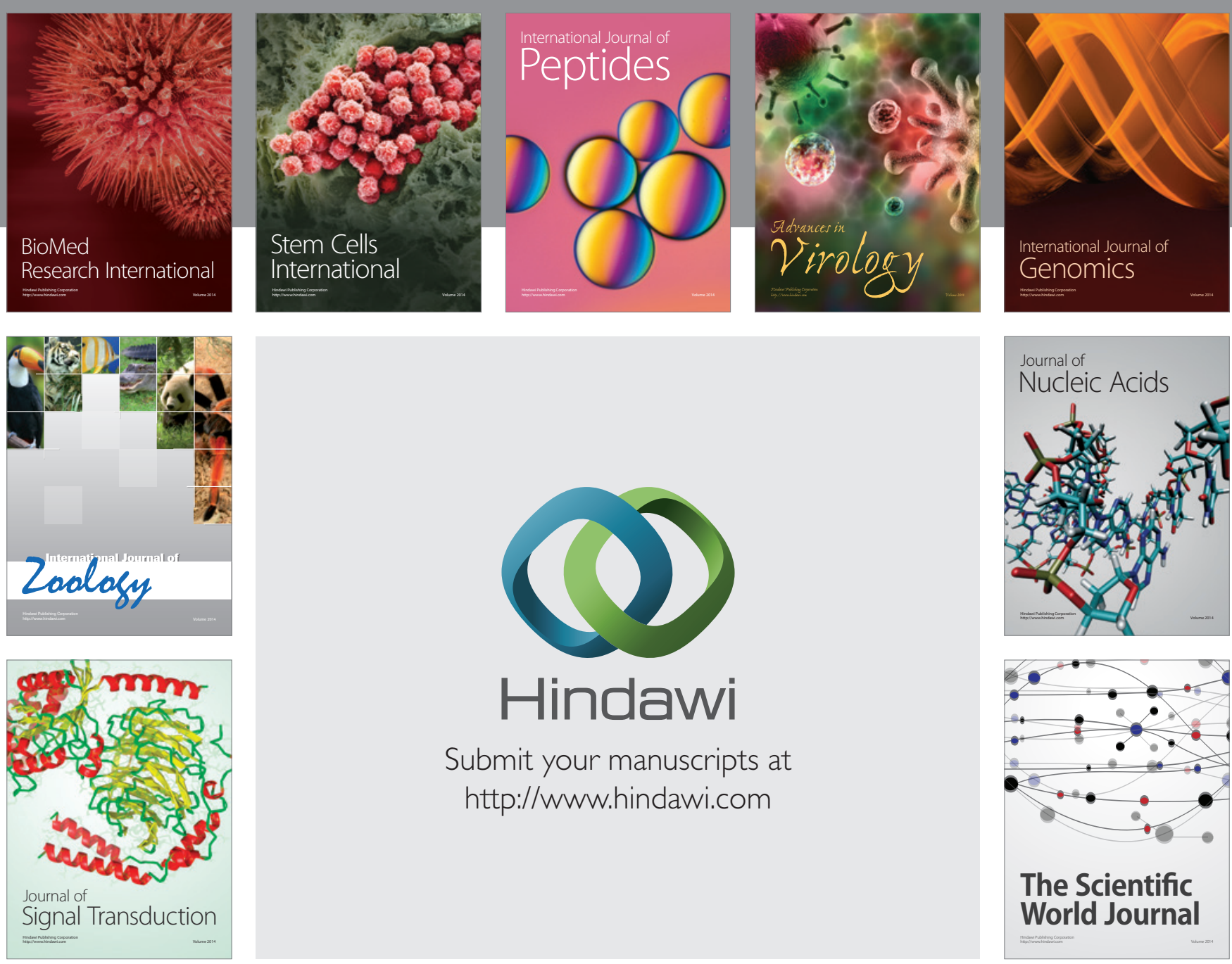

Submit your manuscripts at

http://www.hindawi.com
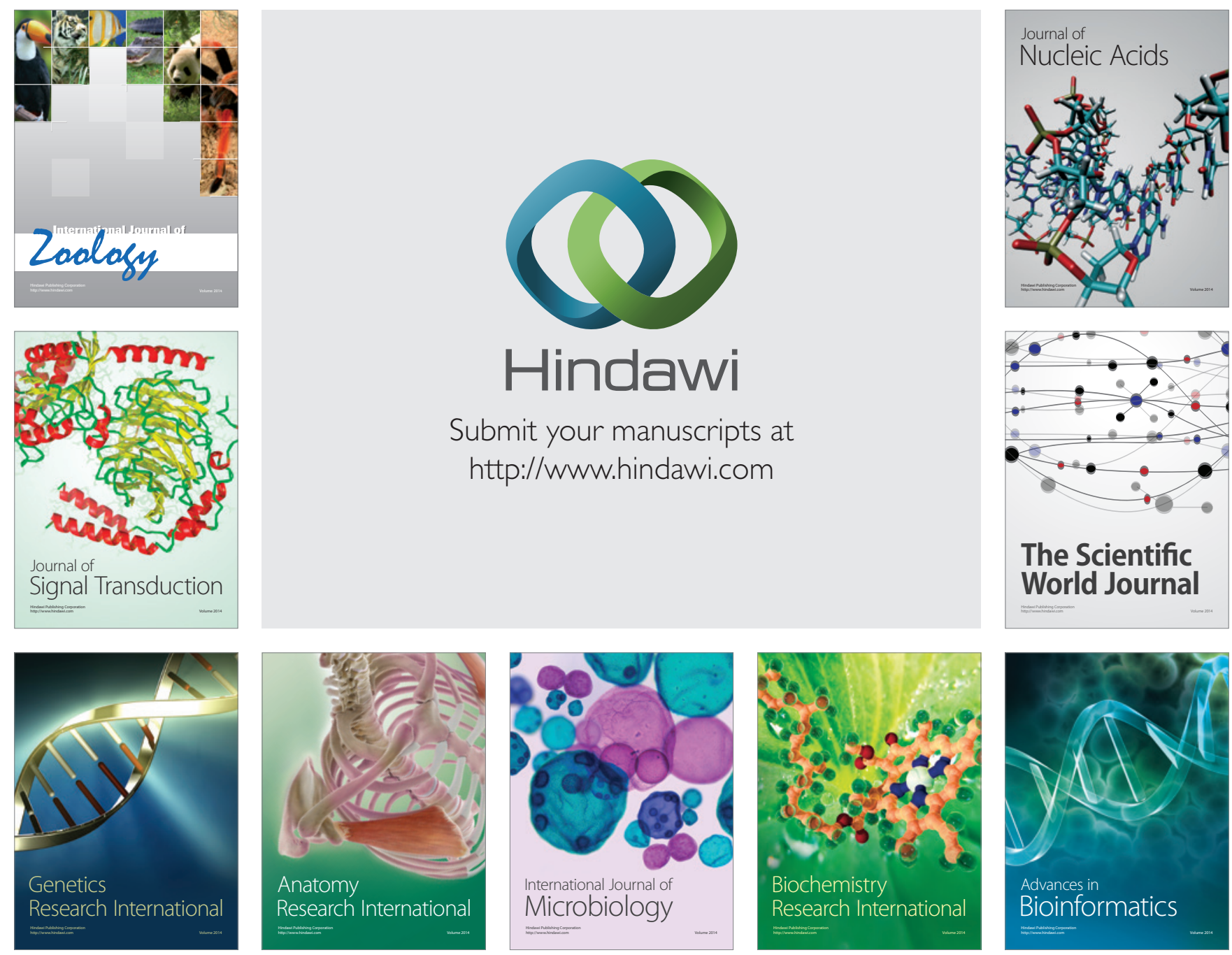

The Scientific World Journal
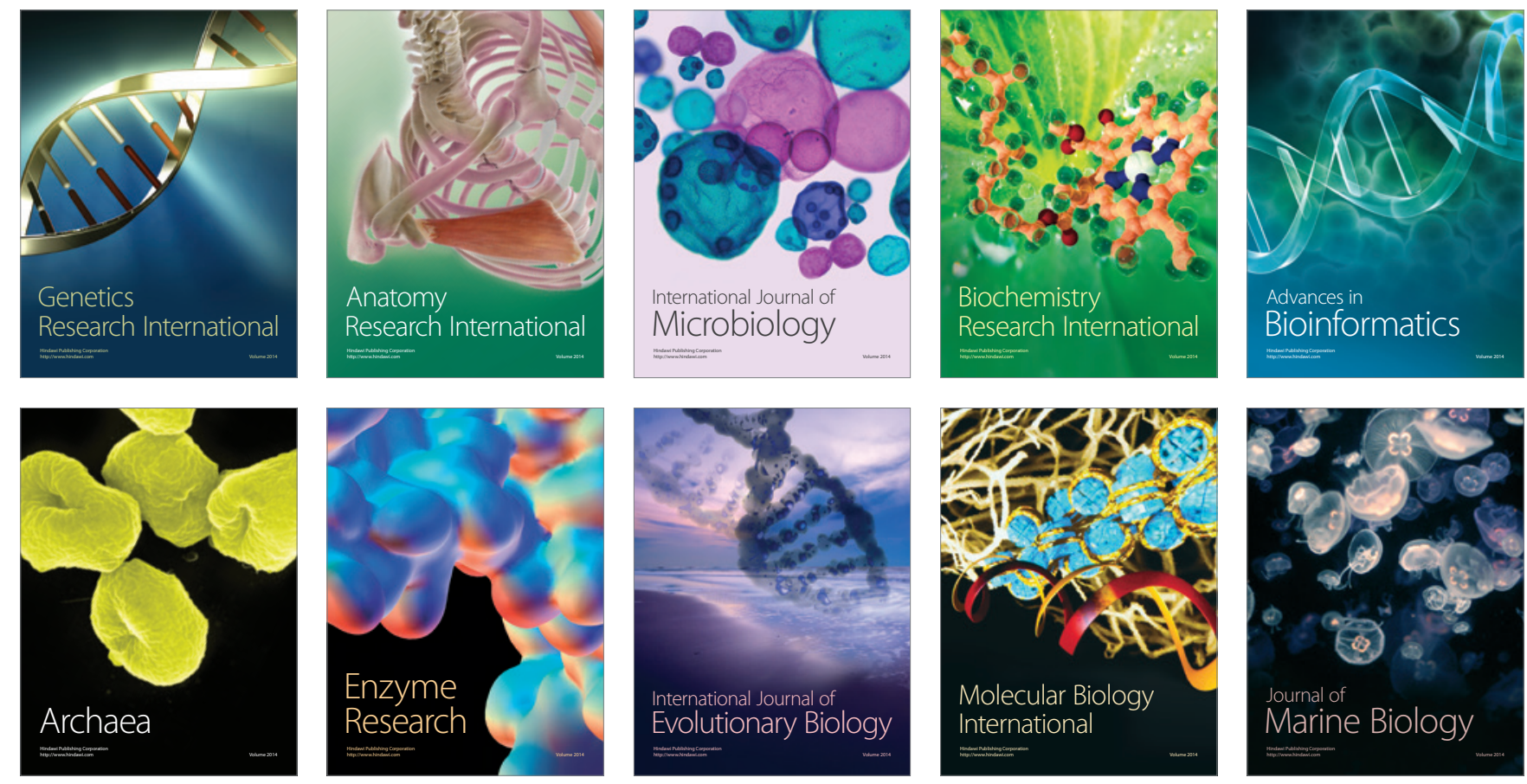